\title{
Effect of ambient temperature on fat oxidation during an incremental cycling exercise test
}

Carlos Ruíz-Moreno, Jorge Gutiérrez-Hellín , Jaime González-García , Verónica Giráldez-Costas, Diego Brito de Souza \& Juan Del Coso

To cite this article: Carlos Ruíz-Moreno , Jorge Gutiérrez-Hellín , Jaime González-García , Verónica Giráldez-Costas, Diego Brito de Souza \& Juan Del Coso (2020): Effect of ambient

temperature on fat oxidation during an incremental cycling exercise test, European Journal of Sport 
Effect of ambient temperature on fat oxidation during an incremental cycling exercise test

Running head: Fat oxidation rate and ambient temperature

Type of paper: Original research

Authors: Carlos Ruíz-Moreno ${ }^{1}$, Jorge Gutiérrez-Hellín ${ }^{2}$, Jaime González-García ${ }^{1}$, Verónica Giráldez-Costas ${ }^{1,}$ Diego Brito de Souza ${ }^{1}$ and Juan Del Coso ${ }^{3}$.

${ }^{1}$ Exercise Physiology Laboratory, Camilo José Cela University, Madrid, Spain.

${ }^{2}$ Exercise and Sport Sciences, Faculty of Health Sciences, Francisco de Vitoria University, Spain.

${ }^{3}$ Centre for Sport Studies, Rey Juan Carlos University. Fuenlabrada, Spain.

Address for correspondence:

Juan Del Coso. https://orcid.org/0000-0002-5785-984X

Rey Juan Carlos University.

C/ Camino del Molino s/n. Fuenlabrada, 28943. SPAIN

E-mail: juan.delcoso@urjc.es 


\section{ABSTRACT}

Aim: The objective of this current research was to compare fat oxidation rates during an incremental cycling exercise test in a temperate vs. hot environment. Methods: Twelve healthy young participants were recruited for a randomised crossover experimental design. Each participant performed a $\mathrm{VO}_{2 \max }$ test in a thermoneutral environment followed by two cycling ramp test trials, one in a temperate environment $\left(18.3^{\circ} \mathrm{C}\right)$ and another in a hot environment $\left(36.3^{\circ} \mathrm{C}\right)$. The ramp test consisted of 3-min stages of increasing intensity $\left(+10 \%\right.$ of $\left.\mathrm{VO}_{2 \max }\right)$ while gas exchange, heart rate and perceived exertion were measured. Results: During exercise, there was a main effect of the environment temperature on fat oxidation rate $(\mathrm{F}=9.35, \mathrm{P}=0.014)$. The rate of fat oxidation was lower in the heat at $30 \% \mathrm{VO}_{2 \max }(0.42 \pm 0.15$ vs. $0.37 \pm 0.13 \mathrm{~g} / \mathrm{min}$; $\mathrm{P}=0.042), 60 \% \mathrm{VO}_{2 \max }(0.37 \pm 0.27$ vs. $0.23 \pm 0.23 \mathrm{~g} / \mathrm{min} ; \mathrm{P}=0.018)$ and $70 \% \mathrm{VO}_{2 \max }$ $(0.22 \pm 0.26$ vs. $0.12 \pm 0.26 \mathrm{~g} / \mathrm{min} ; \mathrm{P}=0.007)$. In addition, there was a tendency for a lower maximal fat oxidation rate in the heat $(0.55 \pm 0.2$ vs. $0.48 \pm 0.2 \mathrm{~g} / \mathrm{min} ; \mathrm{P}=0.052)$ and it occurred at a lower exercise intensity $\left(44 \pm 14\right.$ vs.38 $\left.\pm 8 \% \mathrm{VO}_{2 \max } ; \mathrm{P}=0.004\right)$. The total amount of fat oxidized was lower in the heat $(5.8 \pm 2.6$ vs $4.6 \pm 2.8 \mathrm{~g} ; \mathrm{P}=0.002)$. The ambient temperature also produced main effects on heart rate $(\mathrm{F}=15.18, \mathrm{P}=0.005)$ and tympanic temperature $(\mathrm{F}=25.23, \mathrm{P}=0.001)$ with no effect on energy expenditure $(\mathrm{F}=0.01, \mathrm{P}=0.945)$. Conclusion: A hot environment notably reduced fat oxidation rates during a ramp exercise in the heat. Exercise in the heat should not be recommended for those individuals seeking to increase fat oxidation during exercise.

Keywords: adiposity, indirect calorimetry, body temperature, substrate oxidation, body fat loss. 


\section{INTRODUCTION}

Measurements of human energy expenditure and substrate oxidation have been of interest since the late 1800s (Jeukendrup \& Wallis, 2005). Over the past century, exercise physiologists have learned about the importance of carbohydrate and fatty acids providing energy for active skeletal muscle during aerobic exercise (Evans, Cogan, \& Egan, 2017). In this respect, numerous exercise physiology investigations have tried to determine the best circumstances for optimising fat oxidation during exercise (Achten \& Jeukendrup, 2004) because the selection of fat over carbohydrate within the muscle cell might bring short and long-term sports performance and health benefits. Briefly, previous investigations have established that exercise intensity is the main modulator for the rate of fat oxidation during exercise (Randell et al., 2017) while the curve that explains the relationship between fat oxidation rate and exercise intensity has a negative parabolic shape. In this respect, the maximal rate of fat oxidation (MFO) is normally obtained when exercising at moderate intensity (between 40 to $60 \%$ of $\mathrm{VO}_{2 \max }$ ) (Achten, Gleeson, \& Jeukendrup, 2002; Nordby, Saltin, \& Helge, 2006). Other factors such as exercise duration (Romijn et al., 1993), aerobic fitness (J. Del Coso, Hamouti, Ortega, \& Mora-Rodriguez, 2010), sex (Venables, Achten, \& Jeukendrup, 2005), the pre-exercise meal (Achten \& Jeukendrup, 2003) and the use of some substances such as p-synephrine (Gutiérrez-Hellín \& Del Coso, 2016) and caffeine (Gutiérrez-Hellín \& Del Coso, 2018) can also modify the amount of fat oxidised during exercise. However, another important factor that might modulate fat oxidation during exercise is ambient temperature but studies on this topic are scarce (Febbraio, Snow, Stathis, Hargreaves, \& Carey, 1994; Gagnon et al., 2020, 2013).

Initially, Febbraio et al., (1994) compared the amount of substrate oxidised during 40 min of cycling at $70 \%$ of maximal oxygen uptake $\left(\mathrm{VO}_{2 \max }\right)$ at either 20 or $40^{\circ} \mathrm{C}$, finding that the amount of fat oxidised was reduced by $25 \%$ when exercising in the heat, together with a 
$31 \%$ higher utilisation of muscle glycogen. More recently, fat oxidation curves during exercise on a cycle ergometer and on a treadmill at a $4.6^{\circ} \mathrm{C}$ or $34.1^{\circ} \mathrm{C}$ ambient temperature have been compared (Gagnon et al., 2020). This investigation revealed that MFO was greater at $4.6^{\circ} \mathrm{C}$ during the treadmill exercise and a tendency was also found during cycling. In addition, Fatmax, which is the exercise intensity at which maximal fat oxidation is achieved, increased in both exercise types at $4.6^{\circ} \mathrm{C}$. These data suggest that the $34.1^{\circ} \mathrm{C}$ environment produced a lower fat oxidation rate because it decreased Fatmax. Given this background, it seems safe to conclude that exercising in an environment with a dry temperature above $34^{\circ} \mathrm{C}$ reduces fat oxidation when compared to exercising below $20^{\circ} \mathrm{C}$. However, it is unknown in the effect of a cold environment to enhance maximal fat oxidation and Fatmax is also present in a temperate environment.

Therefore, the objective of the current research was to compare fat oxidation rates during an incremental cycling exercise test in a temperate $\left(18.3{ }^{\circ} \mathrm{C}\right)$ vs. hot environment $\left(36.3{ }^{\circ} \mathrm{C}\right)$ to determine the effect of ambient temperature on maximal fat oxidation and Fatmax. We hypothesised that the fat oxidation-exercise intensity curve would be shifted downwards in the heat when compared to a temperate environment, producing notable reductions in MFO and in Fatmax.

\section{MATERIALS AND METHODS}

Participants. Twelve healthy active young participants volunteered to participate in this investigation (age $=26 \pm 6$ years, body mass $=71.9 \pm 8.9 \mathrm{~kg}$, height $=174 \pm 4 \mathrm{~cm}$, body mass index $\left.=23.6 \pm 2.9 \mathrm{~kg} / \mathrm{m}^{2}, \mathrm{VO}_{2 \max }=54.6 \pm 11.48 \mathrm{~mL} / \mathrm{kg} / \mathrm{min}\right)$. At least ten participants were required to detect a decrease of $0.14 \mathrm{~g} / \mathrm{min}$ in the rate of maximal fat oxidation in the heat when compared to a temperate environment, with a power of 0.80 and two-tailed $\alpha$ level set 
at 0.05 . Participants were considered active because all of them performed at least $60 \mathrm{~min}$ of exercise per day at least 4 days per week although they practised different sports disciplines (road cycling, mountain biking, endurance running). All the participants were non-smokers, had no previous history of cardiopulmonary diseases and had suffered no musculoskeletal injuries in the previous 6 months. They were encouraged to avoid medications, nutritional supplements, and sympathetic stimulants for the duration of the study and compliance was examined using dietary questionnaires. Participants were not heat acclimatised to isolate the effect of ambient temperature on the results of the investigation. One week before the study onset, participants were fully informed of the experimental standards and risks associated with the research, and signed their written informed consent to participate in the investigation. The study was approved by the Camilo José Cela University Research Ethics Committee, in accordance with the Declaration of Helsinki.

Experimental design. In a randomised counterbalanced order, each participant took part in 2 experimental trials separated by 3 days to allow for complete recovery. On one occasion, participants performed the trial in a temperate environment (dry temperature $=18.3$ $\pm 0.9{ }^{\circ} \mathrm{C}$; relative humidity $=59.0 \pm 14.2 \%$ ) while on another occasion participants performed the trial in a hot environment $\left(36.3 \pm 0.7^{\circ} \mathrm{C}\right.$ and $\left.33.3 \pm 13.1 \%\right)$. Except for the difference in dry temperature, the remaining pre-experimental and experimental conditions were meticulously kept constant to fulfil the aim of the investigation. In each trial, participants performed an incremental cycling exercise test composed of 3-min stages and increases of $10 \% \mathrm{VO}_{2 \max }$ per stage (Achten et al., 2002). Gas exchange data, heart rate and perceived exertion were monitored at each stage. Environmental temperature and humidity were recorded at 5-min intervals during the trials using a digital temperature and humidity 
monitor (OH1001, OH Haus, Spain). All the experiments were conducted during the months of May and June 2019.

Pre-experimental procedure. One week before the first experimental trial, participants underwent a 10-min standardised warm-up on a cycle ergometer (SNT Medical, Cardgirus, Spain) before completing a maximal ramp exercise test ( $25 \mathrm{~W}$ increments every 1 min until volitional fatigue). During the test, participants chose a cadence of between 70 and $90 \mathrm{rpm}$ and the test finished when participants were unable to maintain a cadence $>50$ rpm. During the incremental exercise test, oxygen uptake $\left(\mathrm{VO}_{2}\right)$ and carbon dioxide production $\left(\mathrm{VCO}_{2}\right)$ were measured through indirect calorimetry (Metalyzer 3B, Cortex, Germany). $\mathrm{VO}_{2 \max }$ was defined as the highest $\mathrm{VO}_{2}$ value obtained during the test. To normalise exercise intensity in the experimental trials (increases of $10 \% \mathrm{VO}_{2 \max }$ ) among individuals, a regression analysis was performed for each subject for the relationship between $\mathrm{W}$ and $\mathrm{VO}_{2}$ obtained in this test. The incremental exercise test was considered maximal and valid when the end criteria for $\mathrm{VO}_{2 \max }$ were reached at the end of the test: $\mathrm{VO}_{2}$ stabilisation despite increases in exercise intensity $(<0.1 \mathrm{~L} / \mathrm{min}$ increase respect to the previous workload), a respiratory exchange ratio of more than 1.10 , the participant's rating of perceived exertion with the 6-to-20-point Borg scale higher than 19 points and the participant's heart rate over $85 \%$ of the age-adjusted estimate of maximal heart rate (Edvardsen, Hem, \& Anderssen, 2014). This test was performed in a thermoneutral environment dry temperature $=21.0 \pm 0.3{ }^{\circ} \mathrm{C}$; relative humidity $\left.=40.1 \pm 1.9 \%\right)$.

Experimental procedures. Twenty-four hours before each experimental trial, participants refrained from strenuous exercise and adopted a similar diet and fluid intake regimen. Participants were also required to refrain from consuming alcohol, caffeine, tobacco and other stimulants $24 \mathrm{~h}$ before each trial. Before the first trial, participants completed a 24-h dietary record and they replicated the same diet/fluid/exercise routines 
before the second trial with the help of this record. During the experimental trials, the participants arrived at the laboratory $(09.00 \mathrm{am})$ in a fasted state (at least 8 hours after their last meal) and two hours after ingesting $7 \mathrm{~mL} / \mathrm{kg}$ of water. Upon arrival, participants voided, and a urine sample was obtained to measure urine specific gravity (MASTER-SUR, Atago, Japan). A threshold of $<1.020$ for urine specific gravity was used to certify euhydration before the trials. Then, the participants rested supine for $10 \mathrm{~min}$ and resting tympanic temperature were measured (model HDT8208C, Nursal Ear Thermometer, China). An average of three tympanic temperature measurements was used for analysis; $~ 36.1 \pm$ $0.4^{\circ} \mathrm{C}$ for both trials). Participants then dressed in a T-shirt, and shorts (clothing insulation value of $\sim 0.2-0.3$; (Gagnon et al., 2020)) and a heart rate belt (Wearlink, Polar, Finland) was attached to their chest. Afterwards, participants entered a climatic chamber set to produce the temperate vs. hot environment and a standardised 10-min warm-up was performed on the same cycle ergometer used for the pre-experimental procedure. At this moment, participants completed a ramp exercise test on the cycle ergometer (the initial load was set at $30 \% \mathrm{VO}_{2 \max }$, which comprised $10 \% \mathrm{VO}_{2 \max }$ increments every 3 min until reaching a respiratory exchange ratio higher than 1.00. At the end of each 3-min stage, tympanic temperature was measured in the left ear as previously mentioned (J. D. Coso, AguadoJimenez, \& Mora-Rodriguez, 2008). The rating of perceived exertion was measured with the 6-20 point Borg scale (Borg, 1990) and temperature comfort was measured with the scale of the ASHRAE (2017) which goes from -3 point (very cold) to 3 point (very hot; 0 point is the score for a neutral environment). During the test, expired gases were continuously collected with the same breath-by-breath device used for the pre-experimental procedures and representative values of $\mathrm{VO}_{2}, \mathrm{VCO}_{2}$ and respiratory exchange ratio were assessed for each workload by averaging the last $60 \mathrm{~s}$ of each stage (Achten, Venables, \& Jeukendrup, 2003). Certified calibration gases (16.0\% $\mathrm{O}_{2} ; 5.0 \% \mathrm{CO}_{2}$, Cortex, Germany) 
and a 3-L syringe were used to calibrate the gas analyser and the flowmeter before each trial. The rate of energy expenditure and fat and carbohydrate oxidation were calculated from the stoichiometric equations assuming that urinary nitrogen excretion was negligible (Brouwer, 1957; Frayn, 2016). An individually chosen cadence (between 70 and $90 \mathrm{rpm}$ for all participants) was replicated in both experimental trials. In each trial, MFO was individually calculated for each participant as the highest value of fat oxidation rate obtained during the incremental exercise intensity test. The exercise intensity at which MFO was achieved was obtained for each individual and categorised as Fatmax. The day-to-day coefficient of variation of MFO and Fatmax with this protocol is $11 \%$ and 3\%, respectively (Dandanell et al., 2017).

Statistical Analysis. The results of each test were introduced into the statistical package SPSS v20.0 (IBM, USA) and subsequently analysed. The normality of each quantitative variable was initially tested with the Shapiro-Wilk test. All the quantitative variables included in this investigation presented a normal distribution; therefore, parametric statistics were used to determine differences among trials. A two-way ANOVA (intensity $\times$ environment) was used to compare the variables obtained during the incremental test. Mauchly's test was used for sphericity assumption. If this assumption presented a probability of $P<0.05$, the Geisser-Greenhouse correction was used. As the main objective of this investigation was to determine the effect of ambient temperature on the variables under study, only the main effect of environment and the intensity $\times$ environment interaction have been reported in the result section. After a significant $\mathrm{F}$ test, differences between means were identified using Bonferroni post-hoc tests. Paired t-tests were used to compare MFO and Fatmax between environments. The significance level was set at $P<0.05$. The data are presented as mean \pm standard deviation. 


\section{RESULTS}

During exercise, there was a main effect of the environment on the respiratory exchange ratio $(\mathrm{F}=6.38, P=0.032)$ although the interaction between environment and intensity did not reach statistical significance $(\mathrm{F}=3.30 ; \mathrm{P}=0.093)$. The post-hoc analysis revealed a lower higher respiratory exchange ratio values at $30 \%, 60 \%$ and $70 \% \mathrm{VO}_{2 \max }$ (Table 1). There was a main effect of the environment on fat oxidation rate $(\mathrm{F}=9.35, P=$ 0.014) although the interaction between environment and intensity did not reach statistical significance $(\mathrm{F}=2.41 ; \mathrm{P}=0.067)$. The post-hoc analysis revealed a lower fat oxidation rate in the heat at $30 \% \mathrm{VO}_{2 \max }(0.42 \pm 0.15$ vs. $0.37 \pm 0.13 \mathrm{~g} / \mathrm{min} ; P=0.042)$, at $60 \% \mathrm{VO}_{2 \max }$ $(0.37 \pm 0.27$ vs. $0.23 \pm 0.23 \mathrm{~g} / \mathrm{min} ; P=0.018)$ and at $70 \% \mathrm{VO}_{2 \max }(0.22 \pm 0.26$ vs. $0.12 \pm$ $0.26 \mathrm{~g} / \mathrm{min} ; P=0.007$; Figure 1 , upper panel). In addition, there was a tendency for a higher MFO in the temperate environment $(0.55 \pm 0.2$ vs $0.48 \pm 0.2 \mathrm{~g} / \mathrm{min} ; P=0.052)$ which was obtained at a higher exercise intensity $\left(43 \pm 14\right.$ vs. $\left.38 \pm 8 \% \mathrm{VO}_{2 \max } ; P=0.012\right)$. In the temperate environment, 4 participants had their Fatmax at $30 \% \mathrm{VO}_{2 \max }, 4$ at $40 \% \mathrm{VO}_{2 \max }, 1$ at $50 \% \mathrm{VO}_{2 \max }, 2$ at $60 \% \mathrm{VO}_{2 \max }$ and 1 at $70 \% \mathrm{VO}_{2 \max }$. In the heat, 6 participants had their Fatmax at $30 \% \mathrm{VO}_{2 \max }, 3$ at $40 \% \mathrm{VO}_{2 \max }$, and 3 at $50 \% \mathrm{VO}_{2 \max }$. The total amount of fat oxidized in the heat was lower than in the temperate environment $(5.8 \pm 2.6$ vs $4.6 \pm 2.8 \mathrm{~g}$; $P=0.002)$.

\section{$* * *$ Figure $1 * * *$}

There was also a main effect of environment on the carbohydrate oxidation rate ( $\mathrm{F}$ $=6.16, P=0.049)$ with no environment-intensity interaction $(\mathrm{F}=1.751 ; P=0.163)$. The post-hoc analysis revealed a higher carbohydrate oxidation rate in the heat at $60 \% \mathrm{VO}_{2 \max }$ $(2.32 \pm 0.57$ vs. $2.74 \pm 0.72 ; P=0.018$; Figure 1 , lower panel). The total amount of 
carbohydrate oxidized in the heat was not different from the amount of carbohydrate oxidized in the temperate environment $(25.5 \pm 7.8$ vs $32.1 \pm 6.8 \mathrm{~g} ; P=0.070)$. There was no main effect $(\mathrm{F}=0.01 P=0.945)$ nor interaction $(\mathrm{F}=2.03, P=0.111)$ of environment on energy expenditure (Table 1). However, there was a main effect of environment on heart rate $(\mathrm{F}=15.18, P=0.005)$ that produced higher heart rate values in the heat in all pairwise comparisons $(P<0.050)$. Similarly, there was a main effect of environment on tympanic temperature $(\mathrm{F}=25.23, P=0.001)$ with higher tympanic temperatures in the heat in all pairwise comparisons $(P<0.050)$. There was also a main effect of environment on the rating of perceived exertion $(\mathrm{F}=4.05, P=0.007)$ and on the temperature comfort scale $(\mathrm{F}=$ $24.75, P=0.016)$. The result of the pairwise comparisons in these variables is presented in Table 1.

$* * *$ Table $1 * * *$

\section{DISCUSSION}

Previous investigations have suggested that a hot environment (i.e., 40 vs $20{ }^{\circ} \mathrm{C}$ ) might reduce the use of fat while increasing the reliance on carbohydrate oxidation for a fixed exercise intensity (Febbraio et al., 1994). In addition, a cold environment $\left(4.6^{\circ} \mathrm{C}\right.$ vs $34.1^{\circ} \mathrm{C}$ ) may enhance fat oxidation and Fatmax during cycling and treadmill exercise when compared to a hot environment (Gagnon et al., 2020). However, it was unknown in the effect of a cold environment to enhance maximal fat oxidation and Fatmax is also present in a temperate environment. The current investigation is novel because it shows that exercising in a temperate environment $\left(18.3^{\circ} \mathrm{C}\right)$ enhances the rate of fat oxidation at several exercise intensities in comparison to a hot environment $\left(36.3^{\circ} \mathrm{C}\right)$. Specifically, the main findings of this study indicate that an environment of $36.3^{\circ} \mathrm{C}$ produces an overall reduction in the rate of fat oxidation during exercise when compared to the same exercise at $18.3^{\circ} \mathrm{C}$. This main effect was evidenced by the shift downwards of the fat oxidation-exercise 
intensity curve (Figure 1). The rate of fat oxidation was lower in the heat than in the temperate/control situation at $30 \%, 60 \%$ and $70 \%$ of participants' $\mathrm{VO}_{2 \max }$ and, Fatmax was reduced and there was a tendency for a reduced MFO. The lower fat utilisation during exercise in the heat was accompanied by main effects on increasing carbohydrate oxidation rate, heart rate, tympanic temperature, perceived exertion and worsened temperature comfort, as compared to the temperate environment (Table 1). All these outcomes suggest the convenience of selecting temperate-thermoneutral environments, instead of heat, for those exercise routines aimed at maximising fat oxidation. From an applied perspective, 60 min of exercise in an $18.3^{\circ} \mathrm{C}$-environment can increase the amount of fat oxidised by 3 -to- 8 $\mathrm{g}$ in comparison to a $36.3^{\circ} \mathrm{C}$-enviroment, depending on the exercise intensity selected for the routine. However, it is necessary further investigation to determine whether fat oxidation rate during exercise of increasing intensity are similar when comparing temperate and cold environments.

In the current investigation, the hot environment produced a shift in the substrate used for fuel during exercise towards a lower reliance on the oxidation of fat, specifically at high workloads. This shift might be explained by physiological changes measured in the investigation. For instance, tympanic temperature was higher in the heat by $0.5-0.7^{\circ} \mathrm{C}$ at each workload investigated when compared to the temperate environment; although the values of body temperature recorded in this investigation were not indicative of hyperthermia (Nybo \& Nielsen, 2001), the higher body temperature likely meant that the CNS thermoregulatory control increases the sympathetic outflows (Morrison, 2016), ultimately reducing reliance on fat as a fuel for the working muscle (Snitker, Tataranni, \& Ravussin, 1998).

The higher sympathetic activation during exercise in the heat also triggered a direct effect on heart rate (Gordan, Gwathmey, \& Xie, 2015) which was also evident in the 
increased heart rate at each workload, which was always 8-17 beats/min higher for all pairwise comparisons. The effect of the ambient temperature on heart rate was also the result of cardiac output redistribution, because in the heat, cardiac output is divided to satisfy the demands of active muscle but also the thermoregulatory demands of skin blood flow (González-alonso, Crandall, \& Johnson, 2008). Thus, in comparison with the exercise in the temperate environment, where cardiac output is mainly distributed to the working muscle to allow for oxygen and fuel availability, the competitive needs of blood flow in the skin and muscle produced reduced venous return and stroke volume which were responsible for part of the cardiovascular drift found in this investigation (Nybo, Rasmussen, \& Sawka, 2014). However, in the current investigation, it is likely that exercise in the heat would not affect plasma volume changes because the dehydration levels attained at the end of the trials $(0.3 \pm 0.3 \%$ and $0.3 \pm 0.3 \%, P=0.415$, for exercise in the heat and in temperate ambient, respectively) were minor and equal between environments due to the short time that each test lasted (15 $\mathrm{min})$. All this information suggests that exercise in the heat produced several changes in the autonomic regulation as the result of a higher body temperature. The higher sympathetic activation in the heat was likely responsible for the lower reliance on fat oxidation during exercise in the heat, even in the absence of dehydration.

Maximal fat oxidation has been reported to occur between 47 and $75 \%$ of $\mathrm{VO}_{2 \max }$ (Amaro-Gahete et al., 2019; Maunder, Plews, \& Kilding, 2018), although aerobic training increases Fatmax (Nordby et al., 2006), also in the heat (J. Del Coso et al., 2010). In the current investigation, maximal fat oxidation tended to be reduced by $0.11 \mathrm{~g} / \mathrm{min}$ in the heat while Fatmax was effectively reduced in the heat from $\sim 43 \%$ in the temperate environment to $\sim 38 \% \% \mathrm{VO}_{2 \max }$ in the hot environment. Then, the effect of the heat on Fatmax found at each workload has to be added to the effect of ambient temperature, indicating that, exercise in the heat will reduce maximal fat oxidation due to a lower reliance on fat and the 
attainment of Fatmax at a lower exercise intensity. From a practical perspective, the use of lower exercise workloads in the heat cannot prevent the effect of ambient temperature on maximal fat oxidation and the selection of temperate-thermoneutral environments for exercise will promote the use of fat as a fuel. Lastly, the lower ratings of fatigue and higher ratings of comfort in the temperate environment will allow longer exercise durations that will also contribute to an overall greater oxidation of fat during an exercise bout.

Aside from its strengths, the current investigation has some limitations that should be discussed to understand the scope of the research outcomes. Firstly, only two environments that differed in the dry temperature were investigated. Further studies should investigate the effect of environments with temperatures lower than $18^{\circ} \mathrm{C}$ and environments in the range of 18-to- $36^{\circ} \mathrm{C}$ to fully understand the effect of ambient temperature on fat oxidation during exercise. The comparison of cold vs temperate environments, in terms of fat oxidation during exercise may be also interesting to determine the best scenario to maximize fat. In addition, the investigation of other ambient variables such as humidity also deserves further attention. Secondly, we used a cycling ramp test that helps to identify MFO and Fatmax. However, this test is not a typical training routine for exercise practitioners who seek body mass/body fat loss. In addition, we did not include exercise intensities below $30 \% \mathrm{VO}_{2 \max }$ nor post-exercise measurements of substrate oxidation. Future investigations should determine the effect of heat on the total amount of fat oxidised during one bout of exercise in more real training scenarios (e.g., continuous exercise at constant intensity or highintensity interval training), in a wide-range of exercise intensities and including postexercise fat oxidation. Third, we did not obtain blood variables such as lactate concentration, triglycerides concentration and catecholamines concentration that would have helped to understand the mechanism behind the outcomes of this investigation. Lastly, we used tympanic temperature to estimate core temperature which is a valid tool in the conditions set 
for this experiment (J. D. Coso et al., 2008). Still, the use of rectal temperature (through a thermistor) or intestinal temperature (through a telemetric pill) would have helped to enhance the accuracy of core temperature during exercise.

In summary, an environment with a dry temperature of $36.3^{\circ} \mathrm{C}$ notably reduced the rates of fat oxidation during a ramp exercise with workloads at 30 -to- $70 \% \mathrm{VO}_{2 \max }$ when compared to an environment of $18.3^{\circ} \mathrm{C}$ of dry temperature. In addition, MFO tended to be reduced and Fatmax was reduced in the heat. From a practical perspective, the selection of a hot environment would reduce by $13.8 \%$ the total amount of fat oxidized during 1 hour of cycling at Fatmax in the participants of this investigation. These outcomes suggest that the hot environment shifted the fat oxidation-exercise intensity curve downwards and thus, exercise in the heat should not be recommended for those individuals seeking to increase fat oxidation during exercise. Exercising in a temperate environment seems the best choice to increase reliance on fat oxidation during exercise. In this respect, the selection of an environment with a dry temperature close to $18^{\circ} \mathrm{C}$ and the use of prolonged exercise at Fatmax may be one of the most effective exercise routines to maximize the amount of fat oxidized during exercise.

\section{Acknowledgments}

The authors wish to thank the participants for their invaluable contribution to the study.

\section{Conflict of interest}

The authors of this study have not received any support from any organisations for the submitted work. They do not have any financial relationships with any organisations that might have had an interest in the submitted work in the last three years. Lastly, the authors 
have not been involved in any relationships or activities that could seem to have influenced the submitted work.

\section{Financial disclosure}

This investigation did not receive any funding.

\section{Data availability statement}

The data that support the findings of this study are available from the corresponding author upon reasonable request.

\section{REFERENCES}

Achten, J., Gleeson, M., \& Jeukendrup, A. E. (2002). Determination of the exercise intensity that elicits maximal fat oxidation. Medicine and Science in Sports and Exercise. https://doi.org/10.1097/00005768-200201000-00015

Achten, J., \& Jeukendrup, A. E. (2003). The effect of pre-exercise carbohydrate feedings on the intensity that elicits maximal fat oxidation. Journal of Sports Sciences, 21(12), 1017-1024. https://doi.org/10.1080/02640410310001641403

Achten, J., \& Jeukendrup, A. E. (2004). Optimizing fat oxidation through exercise and diet. Nutrition. https://doi.org/10.1016/j.nut.2004.04.005

Achten, J., Venables, M. C., \& Jeukendrup, A. E. (2003). Fat oxidation rates are higher during running compared with cycling over a wide range of intensities. Metabolism: Clinical and Experimental. https://doi.org/10.1016/S0026-0495(03)00068-4

Amaro-Gahete, F. J., Sanchez-Delgado, G., Jurado-Fasoli, L., De-la-O, A., Castillo, M. J., Helge, J. W., \& Ruiz, J. R. (2019, July 1). Assessment of maximal fat oxidation during exercise: A systematic review. Scandinavian Journal of Medicine and Science in Sports, Vol. 29, pp. 910-921. https://doi.org/10.1111/sms.13424 
ASHRAE. (2017). Standard 55 - Thermal Environmental Conditions for Human

Occupancy. Retrieved February 17, 2020, from Thermal enviromental conditions for human occupancy website: https://www.ashrae.org/technical-

resources/bookstore/standard-55-thermal-environmental-conditions-for-humanoccupancy

Borg, G. (1990). Psychophysical scaling with applications in physical work and the perception of exertion. Scandinavian Journal of Work, Environment and Health. https://doi.org/10.5271/sjweh.1815

Brouwer, E. (1957). On simple formulae for calculating the heat expenditure and the quantities of carbohydrate and fat oxidized in metabolism of men and animals, from gaseous exchange (Oxygen intake and carbonic acid output) and urine-N. Acta Physiologica et Pharmacologica Neerlandica, 6(1), 795-802.

Coso, J. D., Aguado-Jimenez, R., \& Mora-Rodriguez, R. (2008). Infrared tympanic thermometry in a hot environment. International Journal of Sports Medicine, 29(9), 713-718. https://doi.org/10.1055/s-2007-989417

Dandanell, S., Prast, C. B., SØndergård, S. D., Skovborg, C., Dela, F., Larsen, S., \& Helge, Jø. W. (2017). Determination of the exercise intensity that elicits maximal fat oxidation in individuals with obesity. Applied Physiology, Nutrition and Metabolism, 42(4), 405412. https://doi.org/10.1139/apnm-2016-0518

Del Coso, J., Hamouti, N., Ortega, J. F., \& Mora-Rodriguez, R. (2010). Aerobic fitness determines whole-body fat oxidation rate during exercise in the heat. Applied Physiology, Nutrition, and Metabolism = Physiologie Appliquee, Nutrition et Metabolisme, 35(6), 741-748. https://doi.org/10.1139/H10-068

Edvardsen, E., Hem, E., \& Anderssen, S. A. (2014). End criteria for reaching maximal oxygen uptake must be strict and adjusted to sex and age: A cross-sectional study. 
PLoS ONE. https://doi.org/10.1371/journal.pone.0085276

Evans, M., Cogan, K. E., \& Egan, B. (2017). Metabolism of ketone bodies during exercise and training: physiological basis for exogenous supplementation. Journal of Physiology. https://doi.org/10.1113/JP273185

Febbraio, M. A., Snow, R. J., Stathis, C. G., Hargreaves, M., \& Carey, M. F. (1994). Effect of heat stress on muscle energy metabolism during exercise. Journal of Applied Physiology, 77(6), 2827-2831. https://doi.org/10.1152/jappl.1994.77.6.2827

Frayn, K. N. (2016). Calculation of substrate oxidation rates in vivo from gaseous exchange. Journal of Applied Physiology.

Gagnon, D. D., Perrier, L., Dorman, S. C., Oddson, B., Larivière, C., \& Serresse, O. (2020). Ambient temperature influences metabolic substrate oxidation curves during running and cycling in healthy men. European Journal of Sport Science, 20(1), 90-99. https://doi.org/10.1080/17461391.2019.1612949

Gagnon, D. D., Rintamäki, H., Gagnon, S. S., Cheung, S. S., Herzig, K. H., Porvari, K., \& Kyröläinen, H. (2013). Cold exposure enhances fat utilization but not non-esterified fatty acids, glycerol or catecholamines availability during submaximal walking and running. Frontiers in Physiology. https://doi.org/10.3389/fphys.2013.00099

González-alonso, J., Crandall, C. G., \& Johnson, J. M. (2008). The cardiovascular challenge of exercising in the heat. Journal of Physiology. https://doi.org/10.1113/jphysiol.2007.142158

Gordan, R., Gwathmey, J. K., \& Xie, L.-H. (2015). Autonomic and endocrine control of cardiovascular function. World Journal of Cardiology, 7(4), 204. https://doi.org/10.4330/wjc.v7.i4.204

Gutiérrez-Hellín, J., \& Del Coso, J. (2016). Acute p-synephrine ingestion increases fat oxidation rate during exercise. British Journal of Clinical Pharmacology. 
https://doi.org/10.1111/bcp.12952

Gutiérrez-Hellín, J., \& Del Coso, J. (2018). Effects of p-Synephrine and Caffeine Ingestion on Substrate Oxidation during Exercise. Medicine \& Science in Sports \& Exercise, 50(9), 1899-1906. https://doi.org/10.1249/MSS.0000000000001653

Jeukendrup, A. E., \& Wallis, G. A. (2005). Measurement of substrate oxidation during exercise by means of gas exchange measurements. International Journal of Sports Medicine, Supplement. https://doi.org/10.1055/s-2004-830512

Maunder, E., Plews, D. J., \& Kilding, A. E. (2018). Contextualising maximal fat oxidation during exercise: Determinants and normative values. Frontiers in Physiology. https://doi.org/10.3389/fphys.2018.00599

Morrison, S. F. (2016). Central control of body temperature. F1000Research, Vol. 5. https://doi.org/10.12688/F1000RESEARCH.7958.1

Nordby, P., Saltin, B., \& Helge, J. W. (2006). Whole-body fat oxidation determined by graded exercise and indirect calorimetry: a role for muscle oxidative capacity? Scandinavian Journal of Medicine \& Science in Sports, 16(3), 209-214. https://doi.org/10.1111/j.1600-0838.2005.00480.x

Nybo, L., \& Nielsen, B. (2001). Hyperthermia and central fatigue during prolonged exercise in humans. Journal of Applied Physiology.

Nybo, L., Rasmussen, P., \& Sawka, M. N. (2014). Performance in the heat-physiological factors of importance for hyperthermia-induced fatigue. Comprehensive Physiology. https://doi.org/10.1002/cphy.c130012

Randell, R. K., Rollo, I., Roberts, T. J., Dalrymple, K. J., Jeukendrup, A. E., \& Carter, J. M. (2017). Maximal Fat Oxidation Rates in an Athletic Population. Medicine and Science in Sports and Exercise, 49(1), 133-140. https://doi.org/10.1249/MSS.0000000000001084 
Romijn, J. A., Coyle, E. F., Sidossis, L. S., Gastaldelli, A., Horowitz, J. F., Endert, E., \& Wolfe, R. R. (1993). Regulation of endogenous fat and carbohydrate metabolism in relation to exercise intensity and duration. American Journal of Physiology Endocrinology and Metabolism, 265(3 28-3).

https://doi.org/10.1152/ajpendo.1993.265.3.e380

Snitker, S., Tataranni, P. A., \& Ravussin, E. (1998). Respiratory quotient is inversely associated with muscle sympathetic nerve activity. The Journal of Clinical Endocrinology and Metabolism, 83(11), 3977-3979.

https://doi.org/10.1210/jcem.83.11.5265

Venables, M. C., Achten, J., \& Jeukendrup, A. E. (2005). Determinants of fat oxidation during exercise in healthy men and women: A cross-sectional study. Journal of Applied Physiology. https://doi.org/10.1152/japplphysiol.00662.2003 


\section{FIGURE LEGENDS}

Figure 1. Rates of fat and carbohydrate oxidation during an incremental exercise test in a temperate vs. hot environment.

Data are mean \pm standard deviation for 12 healthy active individuals Data are mean \pm standard deviation for 12 healthy active individuals who exercised at different exercise intensities relative to their $\mathrm{VO}_{2 \max }$, obtained in a thermoneutral environment. $\left(^{*}\right)$ Hot different from thermoneutral at $P<0.05$. 
Table 1: Respiratory exchange ratio, heart rate, tympanic temperature, energy expenditure, and perceived exertion and thermal stress during an incremental cycling exercise test in a temperate vs. hot environment.

\begin{tabular}{|c|c|c|c|c|c|c|c|c|}
\hline & $\begin{array}{l}\text { Am } \\
\text { bien } \\
t\end{array}$ & $30 \% \mathrm{VO}_{2 \mathrm{ma}}$ & $40 \% \mathrm{VO}_{2 \mathrm{~m}}$ & $0 \% V^{2} O_{\text {max }} 6$ & $\% \mathrm{VO}_{2 \max } 70$ & $6 \mathbf{V O}_{2 \max }$ & $\begin{array}{l}\text { Main } \\
\text { effect of } \\
\text { ambien } \\
t\end{array}$ & $\begin{array}{l}\text { Ambient } \\
\text { xload } \\
\text { interacti } \\
\text { on }\end{array}$ \\
\hline \multirow{2}{*}{$\begin{array}{l}\text { Respiratory } \\
\text { exchange } \\
\text { ratio }\end{array}$} & $\begin{array}{l}\text { Tem } \\
\text { perat } \\
\text { e }\end{array}$ & $0.78 \pm 0.03$ & $0.84 \pm 0.02$ & $0.88 \pm 0.03$ & $0.91 \pm 0.03$ & $0.96 \pm 0.03$ & \multirow[t]{2}{*}{0.032} & \multirow[t]{2}{*}{0.093} \\
\hline & Hot & $0.81 \pm 0.03 *$ & $0.86 \pm 0.02$ & $0.90 \pm 0.03$ & $0.95 \pm 0.03 *$ & $0.99 \pm 0.03 *$ & & \\
\hline \multirow[t]{2}{*}{$\begin{array}{l}\text { Heart rate } \\
\text { (beat/min) }\end{array}$} & $\begin{array}{l}\text { Tem } \\
\text { perat } \\
\text { e }\end{array}$ & $90 \pm 107$ & $107 \pm 10$ & $123 \pm 11$ & $136 \pm 13$ & $148 \pm 9$ & \multirow[t]{2}{*}{0.005} & \multirow[t]{2}{*}{0.144} \\
\hline & Hot & $100 \pm 15^{*}$ & $115 \pm 12^{*}$ & $132 \pm 11^{*}$ & $151 \pm 13^{*}$ & $160 \pm 8^{*}$ & & \\
\hline \multirow{2}{*}{$\begin{array}{l}\text { Tympanic } \\
\text { temperature } \\
\left({ }^{\circ} \mathrm{C}\right)\end{array}$} & $\begin{array}{l}\text { Tem } \\
\text { perat } \\
\text { e }\end{array}$ & $36.0 \pm 0.6$ & $35.9 \pm 0.7$ & $35.9 \pm 0.8$ & $36.0 \pm 0.8$ & $36.1 \pm 0.7$ & \multirow[t]{2}{*}{0.001} & \multirow[t]{2}{*}{0.000} \\
\hline & Hot & $36.1 \pm 0.4^{*}$ & $36.4 \pm 0.4^{*}$ & $36.5 \pm 0.5^{*}$ & $36.7 \pm 0.6^{*}$ & $36.7 \pm 0.5^{*}$ & & \\
\hline \multirow{2}{*}{$\begin{array}{l}\text { Energy } \\
\text { expenditure } \\
\text { (kcal/min) }\end{array}$} & $\begin{array}{l}\text { Tem } \\
\text { perat } \\
\text { e }\end{array}$ & $6.00 \pm 1.29$ & $8.48 \pm 1.47$ & $10.47 \pm 1.82$ & $12.43 \pm 2.01$ & $15.15 \pm 1.82$ & \multirow[t]{2}{*}{0.945} & \multirow[t]{2}{*}{0.111} \\
\hline & Hot & $6.07 \pm 1.37$ & $8.40 \pm 1.76$ & $10.42 \pm 1.87$ & $12.47 \pm 1.84$ & $14.79 \pm 2.14$ & & \\
\hline \multirow[t]{2}{*}{$\begin{array}{l}\text { Borg scale } \\
\text { (A.U.) }\end{array}$} & $\begin{array}{l}\text { Tem } \\
\text { perat } \\
\text { e }\end{array}$ & $7.7 \pm 1.7$ & $9.1 \pm 2.2$ & $11.5 \pm 1.7$ & $14.0 \pm 1.9$ & $15.6 \pm 2.2$ & \multirow[t]{2}{*}{0.007} & \multirow[t]{2}{*}{0.129} \\
\hline & Hot & $8.2 \pm 1.8$ & $10.6 \pm 2.3 *$ & $12.3 \pm 2.3^{*}$ & $14.2 \pm 2.3$ & $16.3 \pm 2.2 *$ & & \\
\hline \multirow{2}{*}{$\begin{array}{l}\text { Temperature } \\
\text { comfort } \\
\text { scale (A.U) }\end{array}$} & $\begin{array}{l}\text { Tem } \\
\text { perat } \\
\text { e }\end{array}$ & $-1 \pm 1$ & $-1 \pm 1$ & $-1 \pm 1$ & $0 \pm 1$ & $0 \pm 1$ & \multirow[t]{2}{*}{0.016} & \multirow[t]{2}{*}{0.238} \\
\hline & Hot & $1 \pm 1 *$ & $1 \pm 1 *$ & $2 \pm 1 *$ & $2 \pm 1 *$ & $3 \pm 1 *$ & & \\
\hline
\end{tabular}

Data are mean \pm standard deviation for 12 healthy active individuals who exercised at different exercise intensities relative to their $\mathrm{VO}_{2 \max }$, obtained in a thermoneutral environment. $(*)$ Hot different from thermoneutral at $P<0.05$. 

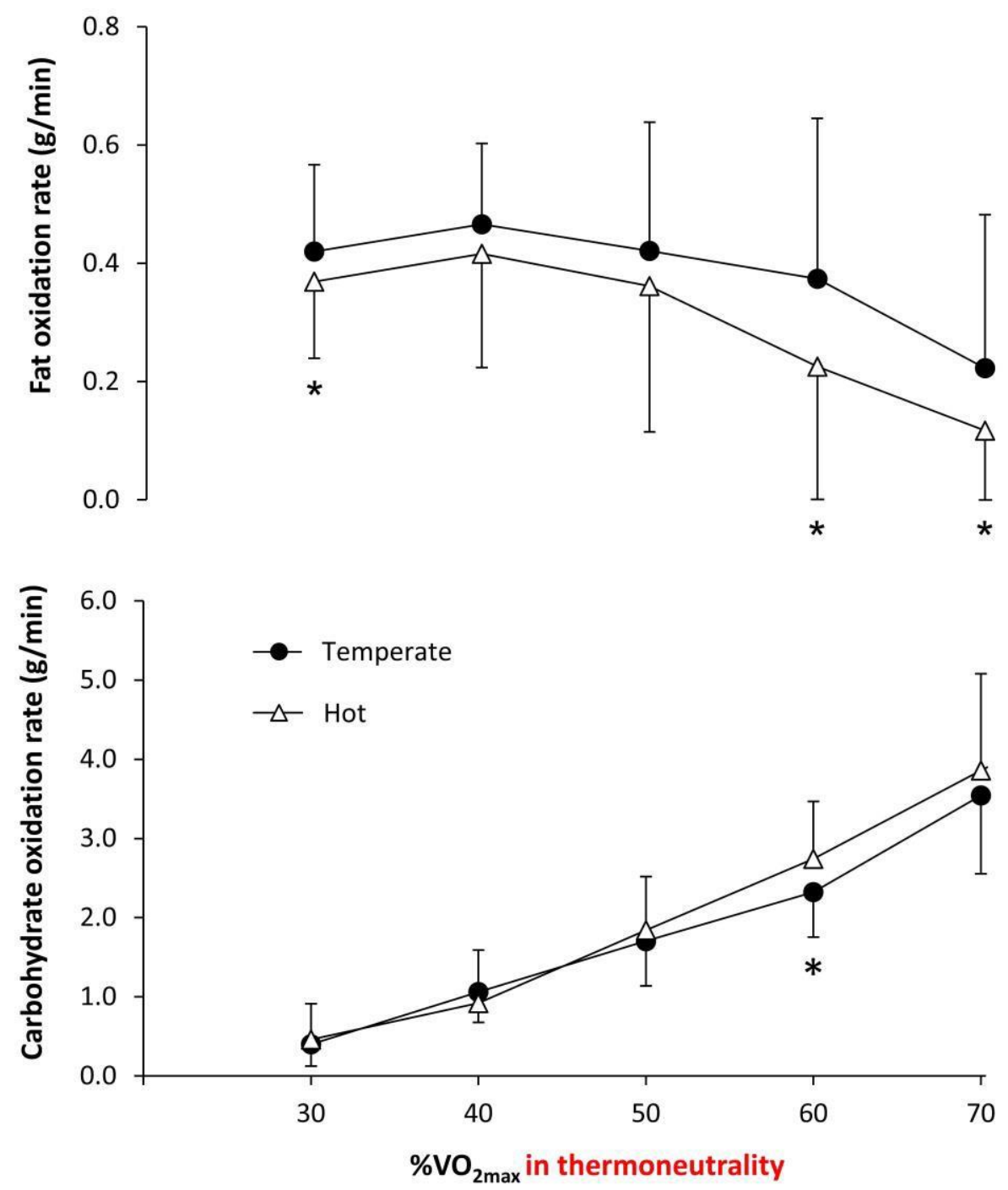